\title{
Interviewing Children Who May Have Been Abused: A Historical Perspective and Overview of Controversies
}

\author{
Kathleen Coulborn Faller \\ University of Michigan
}

tered child syndrome." Their article and other social and political developments led to state and federal legislative activities that, during the mid-1970s, culminated in requirements for mandatory reporting of child maltreatment. Reporting laws target professionals who work with children and currently are accompanied by legal protections for reporters and legal sanctions for those who fail to report.

These laws worked. This is demonstrated by the more than fourfold increase in reports nationally from the time national data began to be collected to the present $-670,000$ cases in 1976 to more than 3 million in 1994 (American Association for Protecting Children, 1987; McCurdy \& Daro, 1994; National Center on Child Abuse and Neglect, 1995). In the beginning, sexual abuse was not necessarily included among reportable conditions in state statutes but gradually was added as states refined their child protection systems and amended their statutes.

When children are abused or neglected, in most instances their physical conditions or living conditions speak for themselves. Medical expertise usually is relied on to determine whether a child's injuries are accidental or nonaccidental. In cases of possible physical neglect, the child's height, weight, degree of cleanliness, appropriateness of dress, and living situation are used to make a decision about the adequacy of parental care. Moreover, often battered children and those with growth failure are too young to talk. Until fairly recently, a typical child protective services (CPS) investigation of a complaint of maltreatment centered around making a home visit, noting the condition of the home, and talking to the parent about the allegations. Children would be observed but not necessarily interviewed (Myers \& Peters, 1987).

CHILD MALTREATMENT, Vol. 1, No. 2, May 1996 83-95 ○ 1996 Sage Publications, Inc. 
In cases of suspected sexual abuse, physical evidence is rare, occurring in only $10 \%$ to $30 \%$ of cases (Bays \& Chadwick, 1993; Faller, 1993). The activity itself occurs in secret with only two people knowing what happened: the victim and the offender. The offender is disinclined to disclose what took place. The logical person to ask, therefore, is the child. Thus child interviewing, as a way of understanding maltreatment, derives from the virtual absence of other alternatives in reports of sexual abuse.

\section{Child Interviewing in the Beginning}

During the early 1980s, when professionals first began talking to children about possible abuse, they had little experience and guidance in this endeavor. Frontline interviewers usually were child protection workers and less frequently were law enforcement officers. Most CPS workers have only bachelor's-level training and not necessarily in a mental health or related field. In addition to staff knowledge deficits, child protective systems are vulnerable to high rates of turnover and workers have high caseloads. Therefore, child interviews were conducted by professionals with little training, few skills, and not much time.

Law enforcement officials were in no better position to interview children. Their interview skills were more likely to be in interrogating suspects than in talking to children about potential trauma. Moreover, for many of them, working with child victims of sex crimes was and is regarded as a stigmatizing assignment with lower status than that of other types of police work (Lanning \& Hazelwood, 1988).

Finally, although mental health training might be considered the optimal training for interviewing children, this has not necessarily been the case. Mental health practitioners may possess good interview and history-taking skills, but their training usually does not teach them how to decide whether or not an event occurred. Typically, when mental health professionals formed conclusions or impressions, these were about issues such as a person's overall functioning, psychiatric diagnosis, personality organization, or problems that require treatment. Like their colleagues in child protection and law enforcement, they usually were not trained to delve into the difficult topic of sexual activity between adults and children.

In this context, interviewers from all disciplines tended to rely on their own subjective judgments about what to do and how to make decisions. Their techniques and strategies were based on personal experience, discipline-specific training, and common sense. Procedures for investigating child sexual abuse lacked uniformity, and decisions often were made based on intuition (Faller \& Corwin, 1995).

One of the outcomes of this period was the evolution of a belief that children were quite unlikely to make up false allegations of sexual abuse (Faller, 1984; Sgroi, 1980). According to the commonsense argument, a child gains nothing by falsely accusing an adult of victimization. In fact, often a child experiences many negative consequences as a result of disclosing genuine sexual abuse: stigmatization, punishment in the form of out-ofhome placement, and having to confront the abuser in court. By contrast, an offender has a vested interest in persuading family, friends, and professionals that the child is disturbed, fantasizing, mistaken, or lying when in fact he or she is guilty of sexual abuse. Similarly, assertions of the offender's innocence by the partner, often the victim's mother, are to be viewed with skepticism because the abuser's guilt has implications for her functioning as a wife and a mother as well as implications for her future life (Faller, 1984).

Out of this argument developed the slogan "believe the child." Specifically, this meant that children's demonstrations, assertions, and affirmations in interviews indicating that they have been sexually abused should be taken at face value. Although the argument addresses common cases of sexual victimization, it does not address all cases. For example, the dynamics and motivations may be different for children caught in the midst of conflictual divorces and for children with high levels of animosity toward the accused.

\section{The Backlash Begins}

The assumption that a child should be believed always had its detractors (e.g., Benedek \& Schetky, 1985; Henderson, 1972), and the heyday of "believe the child" was short-lived. Beginning in 1983, chil- 
dren's accounts of their sexual victimization and the interview skills of those who questioned them began to be challenged. It is worth noting that the cases that launched the backlash involved multiple victims, multiple offenders, and allegations of ritual as well as sexual abuse. Thus the allegations that professionals and the public were asked to believe were quite extraordinary.

The first of these cases involved one admitted offender and several school-aged children from a trailer park in Jordan, Minnesota. Allegations of sexual abuse, pornography, and murder were made against the children's parents and others. Repeated interviews by untrained police officers and the overinvolvement of the prosecutor in the investigation resulted in a belief that coercive interview techniques had elicited false allegations ("The Scott County Case," 1985).

Even more criticism was directed toward the interviewing in the McMartin Preschool case, probably in part because videotapes of these interviews were available. Suggestive interview techniques were blamed for allegedly false accounts of sexual, physical, and ritual abuse by more than 300 children. After the longest and most expensive trial in California history, two accused staff members from the day care center were acquitted of some charges and the jury hung on others.

Although evidence indicates that at least some children were abused by some adults in both of these cases, ${ }^{1}$ the cases have generated a great deal of controversey in the field and are perceived, by the public and some professionals, as false allegations based on poor interviewing.

\section{Consensus Building Begins}

Before these landmark cases, little actually had been written about child interviewing, the notable exception being the pioneering work of Sgroi (Sgroi, Porter, \& Blick, 1982). Shortly after the Jordan and McMartin cases broke, clinical writings about child interviewing began to appear (Benedek \& Schetky, 1987a, 1987b; De Young, 1986; Faller, 1984; Jones \& McGraw, 1987; Klajner-Diamond, Wehrspann, \& Steinhauer, 1987; MacFarlane \& Waterman, 1986; Sink, 1988; Wehrspann, Steinhauer, \& KlajnerDiamond, 1987). Based on their clinical experience, these writers offered advice and made assertions about appropriate interview techniques and criteria for deciding whether sexual abuse had occurred.

More importantly, efforts to gather information about the range of interview practices and to develop some consensus about interview strategies began to appear in the literature. The first was a booklet by
Jones and McQuiston (1985, 1986) published by the C. H. Kempe National Center for the Prevention and Treatment of Child Abuse and Neglect. Before writing this booklet, Jones and McQuiston solicited information from a number of professionals conducting child interviews in cases of suspected sexual abuse and reviewed the existing literature. They made use of research on children's development, memory, and suggestibility. In addition, they incorporated information about current interview practices and criteria used for deciding whether or not children had been victimized. The authors provide an interview protocol and suggest that evaluators examine not only the child's statements for indications of possible sexual abuse but also the child's affective and behavioral functioning, the child's family dynamics, and data from other sources (Jones \& McQuiston, 1986).

In 1985, a National Summit Conference on Diagnosing Child Sexual Abuse was held in Los Angeles and attended by about 100 sexual abuse professionals from throughout the United States. This conference, convened by Corwin (1988), reviewed a proposed "sexually abused child's disorder." The goal was for the sexually abused child's disorder or some version of it to be submitted for possible inclusion in the revision of the Diagnostic and Statistical Manual of the American Psychiatric Association (Corwin, 1988; Faller \& Corwin, 1995). This did not come to pass, but at a follow-up meeting California professionals did develop a catalog of symptoms of possible sexual abuse, differentiating them by developmental stage and the degree of likelihood that the symptoms were related to sexual victimization (Corwin, 1988).

However, the most significant consensus from the summit conference was that there was a need for a new interdisciplinary professional organization focused on child sexual abuse. This consensus eventually led to the founding of the American Professional Society on the Abuse of Children (APSAC).

At about the same time, Conte and colleagues (Conte, Sorenson, Fogarty, \& Dalla Rosa, 1988, 1991) undertook a systematic national study of child interview practices. These researchers first attempted to ascertain who the sexual abuse interview experts were in each state by contacting key professionals and asking them. They then sent these experts a questionnaire covering the assessment process, criteria that might be used to substantiate sexual abuse, and reasons why a child might give a false account. They received responses from 212 professionals from 40 states.

Findings from this survey include the fact that the most commonly used medium in child interviews was anatomical dolls, that only a very small percentage of 
respondents assessed children in the presence of offenders, and that medical evidence and various indicators of sexual knowledge and experience were the most widely endorsed indexes of the probability of sexual abuse. In addition, certain characteristics of a child's account, such as consistency, idiosyncratic detail, a progression of sexual activity, and an ability to distinguish fact from fantasy, were endorsed as important indicators of veracity by large percentages of the respondents.

Conte and colleagues expressed concerns about the responses of the experts in their study because, in some instances, their beliefs were not empirically based and, in others, the presence or absence of the characteristic could be variously interpreted. This study did, however, describe the state of the art in child interviewing and level of uniformity of practice.

In 1986, APSAC was founded. This is a multidisciplinary organization started in.part to refine the professional response to child sexual abuse. A major undertaking of APSAC has been to develop consensus on guidelines for practice related to various aspects of child abuse work. This consensus-building process involves bringing together key professionals who develop drafts of guidelines for practice that are sent to the membership and others for their comments. A final version is produced and passed by APSAC's board of directors. The first set of guidelines to be developed addressed psychosocial evaluation of children who may have been sexually abused (APSAC, 1990). These guidelines contain sections that address the following aspects of child interviewing: (a) who should conduct such evaluations, (b) the components of an evaluation, (c) the interviewing structure and process, (d) tools to be used in the interview, and (e) the formation and documentation of conclusions.

Parallel efforts to establish guidelines for practice were undertaken by the American Academy of Child and Adolescent Psychiatry (AACAP, 1988, 1990), whose guidelines presently are undergoing their third revision. More recently, APSAC (1995) has published guidelines for the use of anatomical dolls, which is discussed in the following section.

\section{GURRENT CONTROVERSIES}

Although progress has been made in child interview strategies over the past 15 years, controversies remain. These controversies can be divided into four related and, in some instances, overlapping categories: (a) the ability of the interviewer to conduct a competent interview, (b) the competence of the child to describe actual events, (c) interview structure and process, and (d) decision making about the likeli- hood of sexual abuse. These all are very complex issues and cannot be completely addressed in this article. Rather, major aspects of each of these issues are summarized, relevant writings and research are cited, and observations are offered. These controversies are ongoing.

\section{The Ability of the Interviewer to Conduct a Competent Interview}

A spectrum of professionals conduct interviews of children who may have been sexually abused. These include child protection workers, law enforcement officers, specially trained or designated forensic interviewers, and mental health professionals with advanced degrees who have chosen sexual abuse diagnostic and therapeutic work as their specialty. Forensic interviewers may be located in children's advocacy centers, hospital-based sexual abuse assessment programs, multidisciplinary teams, and other programs.

Much of the criticism related to interviewer competence has been leveled against child protection and law enforcement, and some guidelines do not include them as appropriate personnel for evaluating allegations of sexual abuse (AACAP, 1990). However, they are the only professionals mandated by law to conduct these investigations.

Interviewers who assess and investigate child sexual abuse have been criticized as sources of false allegations of sexual abuse by virtue of their poor interview practices (e.g., Gardner, 1992b; Underwager \& Wakefield, 1988). A good deal less frequently, these professionals are cited for failure to discover existing sexual abuse or for conducting poor interviews that prevent successful intervention in bona fide cases of sexual abuse (Humphrey, 1985). However, the latter problems may be more common.

An extreme expression of the belief that interviewers foster false allegations is that of Gardner (1991, 1992a, 1992b). He calls interviewers "validators," a pejorative term, and says they are poorly educated, poorly trained, and involved in sexual abuse assessments for a variety of inappropriate motives. For example, Gardner suggests that they may be survivors of sexual abuse working out their own issues, sexually inhibited individuals ill at ease with their own pedophilia, sadists, paranoids, overzealous feminists, and hypocrites (Gardner, 1992b, pp. 327-334). Further, Gardner states that validators may experience sexual gratification when they imagine an act of sexual abuse and that this sexual problem apparently plays a key role in their need to foster false allegations (Gardner, 1992b). He does not provide empirical support for his 
opinions. Moreover, he describes those who cite research and other literature in support of their assertions as engaging in "specious buttressing" (Gardner, 1991, p. 2).

Ceci and colleagues (e.g., Ceci, Huffman, Smith, \& Loftus, 1994) regard both interviewers and therapists as potential threats to accurate data gathering and potential sources of false allegations. They state that they have reviewed notes, audiotapes, and videotapes from hundreds of interviews that document the use of inappropriate, leading, and suggestive practices that culminate in the construction of false allegations. As is described later, these researchers have conducted numerous analog studies from which data are available. However, they have not provided data to support the suggested link between inappropriate interviewer practices and outcomes.

To date, few systematic efforts have been made to gather data on inappropriate interview practices. (Two studies will appear in the Child Maltreatment special sections on child interviewing.) Everson (1995) has reported preliminary results from 97 taped interviews of CPS investigations. The primary goal of the study was to look for "concerning techniques" in the use of anatomical dolls. Although Everson and Boat (1994) found that most interviews contained at least one problem use of the dolls, only a few were considered clinically significant, that is, capable of compromising interview findings. The most common of these was interrupting the child's ongoing verbal disclosure in an effort to gain a demonstration with the dolls, a practice they advise against.

One problem in assessing the role of inappropriate interviewer practices is that assertions that bad interviewing caused false allegations often occur in the context of litigation. Examples of high-profile cases in which this has happened are the Country Walk case (Ceci \& Bruck, 1995; Hollingsworth, 1986), the Kelly Michaels case (Mansell, 1990; Rabinowitz, 1990), and the Little Rascals case (Ceci \& Bruck, 1995). What this means is that interviewer behavior might be open to different interpretations depending on which side the commentator is on. In addition, although in some of these cases inappropriate interview techniques have been documented (e.g., in the Kelly Michaels case [Leichtman \& Ceci, 1995; Myers, 1994]), it is less clear that the inappropriate interviews led to completely fabricated allegations of sexual abuse by children.

\section{The Competence of the Child to Describe Actual Events}

Accompanying concern about the ability of interviewers is concern about the ability of children to describe what actually happened. There are several often related issues: children's willingness to describe their experiences, their memories, their vulnerability to suggestion, and their propensity to lie and fantasize. Although there is some relevant research on actual cases of sexual abuse, much of our knowledge about these issues derives from analog studies, that is, documented naturally occurring or staged events in children's lives about which they are questioned in a variety of ways (e.g., with open-ended, leading, or misleading questions).

In judging the relevance of this research, it is important to consider the ecological validity of analog research or the extent to which the study circumstances are similar to actual experiences of sexual abuse. Events involving active participation rather than passive observation, people rather than toys or other objects, body touch (particularly genital touch), and secrecy have greater ecological validity.

However, sexual abuse occurs in many different ways, with wide variations in circumstantial and interpersonal dynamics. In addition, ethical and human subject constraints prevent the simulation of some of the most salient aspects of sexual abuse experiences. These include the power relationship between victim and offender, the intrusiveness of the activity, manipulations, coercion, threats, and the life consequences of disclosure. Therefore, achieving ecological validity is a very great challenge indeed.

Children's reluctance to disclose. Professionals directly involved in child interviewing have been more concerned than those with other roles about the issue of children's reluctance or inability to disclose genuine sexual abuse. The proposed etiologies of disclosure failures include embarrassment, feelings of culpability, avoidance coping, and fear of consequences of disclosure (Faller, 1988).

Research on actual cases, substantiated by means other than child disclosure (e.g., offender confession, venereal disease), indicates that false negatives and resistance to reporting abuse are problems of some magnitude (Faller, 1988; Lawson \& Chaffin, 1992; Sorenson \& Snow, 1991). For example, taking a sample of 116 high-certainty cases, Sorenson and Snow found that $72 \%$ of children initially denied sexual abuse, although over several interviews all but $4 \%$ disclosed. In addition, $22 \%$ of children in Sorenson and Snow's sample recanted during the disclosure process. Lawson and Chaffin examined disclosures of 22 children found positive for sexually transmitted disease. When interviewed by a skilled practitioner, only $43 \%$ of these children disclosed and a mere $17 \%$ 
of children whose parents were unsupportive described sexual abuse.

Analog studies that involve genital touch (Katz, Schonfeld, Levanthal, \& Cicchetti, 1995; Saywitz, Goodman, Nicholas, \& Moan, 1991) and those that include requests for secrecy (Clarke-Stewart, Thompson \& Lapore, 1989) have similarly found that children fail to report their experiences. For example, Saywitz and colleagues interviewed 72 5- and 7-yearold girls, half of whom received a genital and anal exam and half of whom received a scoliosis exam, both in the course of a general medical exam. In response to an open-ended question about what happened, all children who had the scoliosis exam mentioned it. By contrast, in the private parts exam condition, $78 \%$ failed to mention the genital exam and $89 \%$ failed to mention the anal exam. Even with a direct question ("Did the doctor touch you here?"), not all children responded affirmatively $(86 \%$ affirmed the genital exam and $69 \%$ affirmed the anal exam). There were also three false positives, that is, children who received the scoliosis exam but responded affirmatively to the direct question about the genital or anal exam.

Children's memory problems. The accuracy of children's recall is another concern raised about their reports of sexual abuse. Neither adults nor children have total recall of past events. Moreover, remembering experiences is a complex phenomenon involving a series of processes: memory acquisition, storage, interpretation, and retrieval. Analog studies suggest some aspects of memory that may pose difficulties for interviewing children about sexual abuse.

Children may fail to attend to events and details that are salient to adults, and therefore memory is not acquired. Attention failures are likely the source of some errors by children in analog studies (Brainerd \& Orenstein, 1991). In addition, researchers have noted, especially with young children, that reporting ability is better for central events than it is for peripheral events (Goodman, Hirschman, Hepps, \& Rudy, 1991). In a situation of sexual abuse, attention failures may involve key details about the victimization such as whether or not the penis was erect. The absence of details in the child's account may lead to questions about the veracity of the abuse.

Analog studies indicate that preschoolers' memory storage capacity is as good as that of adults (Brainerd \& Orenstein, 1991; Fivush, 1993). However, memories originally stored fairly completely may deteriorate over time (Goodman \& Clarke-Stewart, 1991). With few exceptions (e.g., Fivush \& Shukat, 1995; Goodman \& Clarke-Stewart, 1991; Steward \& Steward, in press), analog studies test recall over a few days or weeks. In cases of possible sexual abuse, interviewers may be asking children to report experiences that happened months or years ago. Based on knowledge about memory deterioration, questions have been raised about the accuracy and completeness of children's reports.

Some traumatic memory researchers and clinicians have countered that traumatic memory (e.g., memory of sexual abuse) is fundamentally different from narrative memory as represented in analog studies. Traumatic memory is more likely to be sensorimotor than verbal. It is not subject to forgetting, although it may be dissociated (e.g., Bremner, Krystal, Southwick, \& Charney, 1995; Van der Kolk, 1994; Van der Kolk \& Fisler, 1995). Understanding the issue of memory deterioration versus dissociation is further complicated by an appreciation that not all sexual abuse is experienced as traumatic (Conte \& Berliner, 1986).

In fact, the issue of memory over time may be very complex indeed. In a longitudinal study of preschoolers, Fivush and Shukat (1995) found that children's reports of a memorable event, a visit to an amusement park, were quite accurate and increased in sophistication as they grew older. However, the details they recalled at different ages were inconsistent, with very little overlap in recollections from one interview to the next.

Children's interpretation of recollections of sexual abuse may be another obstacle for the interviewer. The more a person knows, the more accurately he or she interprets an experience. Children may have encoding problems with experiences they do not understand (Brainerd \& Orenstein, 1991). This might happen with sexually abusive experiences because children do not usually have background knowledge about sex and sexual abuse. Children may also have trouble interpreting and communicating their experiences because they do not have the language to do so. This may particularly be a problem with sexual activity because children may have no names for the private body parts or words for sexual acts.

Moreover, children may fail to retrieve information in their memories. As already noted, some researchers and clinicians may attribute this problem to dissociation as well as other dynamics. Analog studies suggest that young children have difficulty providing narrative accounts. In response to open-ended questions, the information young children provide is sparse but accurate (Steward \& Steward, in press). They require direct questions to access past experiences (e.g., Goodman \& Clarke-Stewart, 1991; Steward \& Steward, in press). However, accuracy may decrease somewhat 
with direct questions (e.g., Goodman \& ClarkeStewart, 1991).

Children's vulnerability to suggestion. Central to the controversy about children's capacities to report sexual abuse are concerns about their suggestibility. Not only might they be vulnerable to suggestive interviewing by professionals, but they could potentially be programmed by others (e.g., parents) before they are interviewed. Analog studies indicate that children are more suggestible than adults (Ceci \& Bruck, 1993). Nevertheless, a fairly universal finding from such studies is that children are quite accurate in accounts of their experiences when they are not asked leading questions (Ceci \& Bruck, 1993; Clarke-Stewart et al., 1989; Leichtman \& Ceci, 1995).

Interrogation with leading techniques can elicit false positives from preschoolers, however. Young children can be cajoled into endorsing a reinterpretation of an ambiguous event (Clarke-Stewart et al., 1989). With several sessions of programming and suggestion, a minority of preschoolers (less than $20 \%$ ) will assert that they have seen something that they have not (Leichtman \& Ceci, 1995). In addition, children 4 years of age or under are more vulnerable to suggestion than those over age 4 (Ceci, Loftus, Leichtman, \& Bruck, 1995; Leichtman \& Ceci, 1995). Especially problematic are children age 3 or under, a substantial minority of whom may provide false positives to direct questions such as "Did the doctor touch your [child's term for penis]?" (Bruck, Ceci, Francoeur, \& Renick, 1995; Gordon et al., 1993).

Children's propensity to lie and fantasize. Closely related to the issue of suggestibility is the issue of lying and fantasizing. Some who question abuse allegations have proposed that children may falsely declare that they have been sexually abused to gain attention and that the more positive reinforcement children receive, the more they elaborate on their abuse. In fact, this argument has been proposed to explain children's accounts of ritual abuse (personal communication with K. Lanning, 1994). Some writers have likened children's elaboration of accounts over time to "shaping," which occurs in behavior therapy. In shaping, the clinician rewards successive approximations of the target behavior (Underwager \& Wakefield, 1988). No data on abuse allegations have been provided by the proponents of this theory, however.

In fact, analog studies that compare the effects of a positively reinforcing interviewer to those of a noncommittal or intimidating interviewer do not lend support to this theory (Carter, Bottoms, \& Levine, in press; Goodman, Bottoms, Schwartz-Kennedy, \& Rudy, 1991). Rather, they find that a positively rein- forcing interview style either improves accuracy, especially with younger children (3-to 4-year-olds), or does not affect the amount and accuracy of information provided (e.g., with older children such as 5- to 7-yearolds) (Carter et al., in press; Goodman, Bottoms, Schwartz-Kennedy, \& Rudy, 1991).

On the other hand, a substantial minority of preschoolers can be persuaded to affirm that they experienced events suggested by an interviewer (Ceci et al., 1995). Children in Ceci and colleagues' study were falsely told that their parents said the children had had certain experiences when younger. The researchers then encouraged the children to fantasize about the details of these events over 11 half-hour sessions. Children were most likely to incorrectly endorse a neutral observed event (seeing another child waiting at a bus stop) and least likely to endorse a negative participant event (falling off a tricycle and getting stitches) (Ceci et al., 1995).

Finally, at least a few children can be encouraged over time with suggestive techniques to provide entirely fabricated accounts of personal experiences (e.g., getting a hand caught in a mousetrap) (Ceci, 1993).

Discerning whether children are lying in actual reports of sexual abuse is a real challenge because it is difficult to be sure that no sexual abuse did in fact occur. Independent indicators of the absence of sexual abuse that might be used in research are more difficult to identify than are independent indicators of its presence. Therefore, researchers who have attempted studies of real-world cases have employed clinical characteristics of children's accounts to rate cases as true or false, a practice that is somewhat tautological. This research suggests that false allegations by children are rare, occurring in $1 \%$ to $10 \%$ of reports (Faller, 1988; Jones \& McGraw, 1987; Tufts New England Medical Center, Division of Child Psychiatry, 1984). Older children, particularly adolescents, may be more likely to make false reports.

Concerns about children fantasizing are based on a belief that children cannot differentiate fact from fantasy. Although interviewers sometimes encounter the intrusion of fantasy into children's accounts of their abuse (Everson, 1994), they have criteria that can help differentiate fantasy from experience. Specifically, children, without exposure to sex, do not have the knowledge to provide detailed descriptions of sexual acts, and children generally provide fantasy material about desired, not dreaded, events (Faller, 1988).

Gardner (1991) rejoins by saying, "Children normally exhibit just about any kind of sexual behavior 
imaginable: heterosexual, homosexual, bisexual, and autosexual" (p. 9). To again quote Gardner, "A fouryear-old girl, for example, may harbor, among her collection of polymorphous perverse fantasies, thoughts of some kinds of sexual encounters with her father" (Gardner, 1992b, p. 125).
In determining who, other than the child, is to be involved in the assessment process, variability appears to be needed. The circumstances of the alleged abuse and the nature and extent of the child's interview disclosures, among other things, influence who else should be interviewed.

\section{Interview Structure and Process}

Many aspects of the structure and process of child interviews have been sources of controversy: who should be interviewed, the number of interviews to conduct, record keeping, questioning strategies, and the use of media such as anatomical dolls.

Who should be interviewed? The core of the controversy regarding who should be interviewed is whether a child interview is sufficient, in and of itself, as a source of information to make a decision about sexual abuse. With few exceptions (Blush \& Ross, 1986; Haynes-Seman \& Baumgartner, 1995), professionals regard the child interview as an essential part of determining the likelihood of sexual abuse (Conte et al., 1991; De Young, 1986; Faller, 1988, 1990, 1993; Sgroi et al., 1982; Sink, 1988; Yuille, 1988).

However, experts differ about whether others need be interviewed and, if so, who else and for what purposes. For example, some fault interviewers who fail to interview the alleged offender and the nonaccused parent in intrafamilial sexual abuse, especially if the parents are separated or divorced (AACAP, 1990). Others argue that interviews with these individuals are useful in understanding the child's relationships with family members and other issues but not necessarily in understanding whether or not the child has been sexually abused (APSAC, 1990; Faller, $1984,1988,1990)$. A very small number of professionals advocate putting the child in the room with the alleged offender as a way of determining the veracity of the allegation (Gardner, 1992b; Green, 1986; Haynes-Seman \& Baumgartner, 1995), but other professionals have raised questions about both the ethics and the efficacy of this practice (APSAC, 1990; Corwin, Berliner, Goodman, Goodwin, \& White, 1987; Faller, Froning, \& Lipovsky, 1991; Hanson, 1988).
How many interviews? There are concerns about both too few (Sorenson \& Snow, 1991) and too many interviews (AACAP, 1990). Too few interviews may mean that too little time is devoted to adequately assess the allegation, leading to a precipitous decision that either the child was or was not sexually abused. Too many interviews might result in unduly influencing the child (AACAP, 1990). Most protective services and law enforcement investigations and many programs that do a high volume of sexual abuse assessments rely primarily on a single interview. Yet research on highcertainty cases suggests that disclosure is an incremental process requiring two or more sessions (Sorenson \& Snow, 1991).

There does not seem to be a single solution for this issue. The appropriate number of interviews will depend on the role of the interviewer, the length of interviews, and their purposes. For example, the number of interviews might vary based on whether the goal is to merely assess for possible sexual abuse, to understand its full extent, or to examine other aspects of child functioning. Another factor that might determine the number of interviews is whether the child is safe from possible sexual abuse while several interviews are conducted. Finally, the appropriate number of interviews might be influenced by whether the interview(s) is used to rule in or rule out sexual abuse.

How to keep records? The major controversy concerning recording is to videotape or not to videotape. Although videotaping generally offers the most complete record of the child interview, may reduce the number of interviews, may result in a confession or plea, or may reveal any blatantly inappropriate practices, it is not the answer to all of the uncertainties and difficulties associated with child interviews. Some professionals advise against videotaping because it sets standards for child interviews regarding sexual abuse 
that do not exist for other crimes (personal communication with L. Berliner, 1993). Further, the minutia of how a child was interviewed may take precedence over what the child said, and videotapes may get into the wrong hands (see Faller, 1996; Myers, 1992).

What questioning strategies to use? Questioning strategies have long been a source of controversy. The concern is that leading, suggestive, and coercive questions may result in false allegations of sexual abuse. Most professionals writing about interviewing advise against using leading questions, but there is some disagreement about what constitutes a leading question (Faller, 1990; White \& Quinn, 1988).

Several writers have proposed questioning strategies (Boat \& Everson, 1988; Boychuk \& Stellar, 1992; Bull, 1995; Faller, 1993; Myers, 1992; Yuille, 1988). All agree that the interviewer should start with openended inquiry and resort to more close-ended questions when the open-ended ones are inadequate to make a determination about possible sexual abuse. In addition, all of these writers are of the opinion that direct questions may at some point be needed.

Analog studies have addressed the issue of the kinds of information different sorts of questions elicit and its accuracy (e.g., Leichtman \& Ceci, 1995; Saywitz et al., 1991). The limitation, noted earlier, that researchers are not asking about sexual abuse applies to the findings. However, some of this research is instructive (e.g., Saywitz and colleagues' [1991] study, cited earlier, on children's disclosures of genital and anal touch during the course of a medical exam). This research suggests that most children will not mention private parts touch in response to open-ended questions. They require direct questions, and even then some do not affirm private parts touch. However, direct questions may also elicit a small number of false positives.

Research that employs highly leading and suggestive questions is enlightening primarily in its demonstration of most children's resistance to leading questions (Ceci et al., 1995). However, because leading and suggestive questions are not ones recommended for child interviewing, these studies are less helpful in informing interview practices.

Some of the research on misleading questions is instructive, but other research is less so. For example, studies in which a child is asked to show where he or she was touched when no touching occurred (Bruck et al., 1995; Goodman \& Clarke-Stewart, 1991) provide important lessons. At least some children, especially young ones, will provide inaccurate information to misleading questions. Less useful are findings from experiments using misleading questions about peripheral events (e.g., "What color was the nurse's scarf?" when the nurse was not wearing one) (Goodman, Hirschman, Hepps, \& Rudy, 1991).

Very little research has been done with questioning protocols involving actual cases. But in a study of 70 children ages 5 to 10 suspected of being sexually abused, DeVoe (1995) found that only 1 child disclosed sexual victimization in response to general or open-ended questions. The vast majority of those who disclosed did so in response to focused questions (direct inquiry about a person [e.g., "Tell me about your daddy"], body touch [e.g., "Did anything ever happen to your peepee?"], circumstances of the abuse [e.g., "What do you do when he babysits?"], or circumstances of prior disclosure ["Was there something you told your teacher about?"]).

How to use media? Interviewers often use media such as drawings and dolls to facilitate communication with children, especially young children. Most of the controversy regarding media has centered around anatomical dolls. The challenges to the dolls are that they are suggestive because they have enlarged genitals or because they have genitals at all and consequently lead children to make false allegations.

One study that examined genital and breast size on several sets of adult and child anatomical dolls generally did not find them overly large (Bays, 1990). Research that has assessed the reactions of children without histories of sexual abuse to anatomical dolls indicates that they do not serve as a stimulus to sexualized behavior for sexually naive children but do serve as a stimulus for sexually knowledgeable children, which is what interviewers would hope they would do (Everson \& Boat, 1994; Sivan, Schor, Koeppl, \& Noble, 1988).

However, anatomical dolls do not always elicit sexualized behavior from children with a history of sexual abuse (August \& Foreman, 1989; Jampole \& Webber, 1987; White, Strom, Santilli, \& Halpin, 1986). Further, the demonstration of sexual acts with dolls does not always signal sexual abuse because children can learn about sex from experiences other than sexual abuse (Everson \& Boat, 1994).

Finally, several analog studies indicate that anatomical dolls, especially when used in conjunction with questions, assist children's disclosures of body touch (Aman \& Goodman, 1990; Katz et al., 1995; Saywitz et al., 1991; Steward \& Steward, in press).

There are also a few disconfirming studies regarding the efficacy of the dolls (e.g., Bruck et al., 1995; Cohn, 1991). For example, Bruck and colleagues found that anatomical dolls were not superior to use of the child's body or direct questions in eliciting information about body touch with children age 3 or younger. Both dolls and body use yielded high rates 
of false negatives (about 50\%). There were also high rates of false positives with types of demonstration among girls.

APSAC has concluded that the benefits of using anatomical dolls outweigh any costs and has issued guidelines for their use (APSAC, 1995). These guidelines include the research findings on anatomical dolls, appropriate and inappropriate uses of the dolls, how to document data from doll interviews, and the type of training needed by professionals using anatomical dolls.

\section{Decision Making About Sexual Abuse}

There are controversies associated with forming an opinion about the likelihood of sexual abuse. There is even disagreement about whether mental health professionals ought to express such opinions in reports or in court (Melton \& Limber, 1989). Some argue that mental health professionals have no particular expertise in deciding whether an individual is telling the truth. However, this is a minority view and one that promotes lack of candidness on the part of the interviewer. It would be unusual for the interviewer not to form an opinion, and so it seems illogical for the interviewer to withhold it.

A related issue is the degree of certainty with which the interviewer holds that opinion. Jones and McGraw (1987) suggest a continuum of certainty and imply that few cases exist in which the interviewer is either $100 \%$ certain sexual abuse did occur or $100 \%$ certain it did not. However, protective services and legal intervention do not require absolute certainty of abuse.

Over the past 10 years, a number of writers have addressed the issue of how to assess interview and other data to determine the likelihood of sexual abuse (Benedek \& Schetky, 1987a, 1987b; Conte et al., 1991; De Young, 1986; Faller, 1984, 1988; Heiman, 1992; Levanthal, Bentovim, Elton, Trantner, \& Reed, 1987; Sink, 1988; Wehrspann et al., 1987; Yuille, 1988). Some writers focus entirely on child interview findings, but most include some information external to the interview, most often medical evidence (Faller, 1994). Some focus their search for evidence of validity on linguistic characteristics of the child's account (Raskin \& Esplin, 1991; Yuille, 1988), whereas others concentrate on actual information from the child (Benedek \& Schetky, 1987a: Faller, 1988; Sink, 1988). The most frequently cited interview criterion is "affect consistent with the abuse description," followed by "detail about the sexual acts," "advanced sexual knowledge," and "description of an idiosyncratic event" (Faller, 1994). However, only two of these decisionmaking strategies have been subject to research (Faller, 1988; Raskin \& Esplin, 1991; Yuille, 1988).

\section{CONCLUSION}

Professionals in the field have come a long way in 15 years of child interviewing. However, there is still a great deal more to be learned about appropriate techniques, and there are many controversies yet to be resolved.

As noted earlier, the backlash really began in response to some cases that challenged people's credulity. Children reporting these incomprehensible acts and the professionals who interviewed them were the logical targets for those overwhelmed by disbelief.

This skepticism now pervades responses to many or most cases of alleged sexual abuse. A very unfortunate outcome is that often the needs of children who may have been sexually abused become quite secondary and concerns for adults who may be falsely accused become overriding. It is doubtful that these reactions will be overcome by appeals on behalf of children.

The cure for the current skepticism is good practice and good research. Moreover, as much as possible, practice should be driven by research. As already noted, there are two kinds of research that can inform practice: research on real-world cases and analog studies. Both types of research have shortcomings. Researchers studying actual cases face the challenge of finding samples for which they can determine ground truth. On the other hand, researchers conducting analog studies must struggle to find or create circumstances that replicate as much as possible the experience of child sexual abuse.

A review of the relevant research yields literally hundreds of analog studies but no more than two dozen studies of actual cases. This state of affairs is a consequence of research funding guidelines and priorities and the career paths of those who conduct these two types of research. Although more research of both kinds is necessary, real-world research is a priority. More studies like those of DeVoe (1995) and Everson (1995), involving actual practice and children's responses to it, are needed.

Particularly lacking is research on appropriate nonleading techniques for eliciting information from children who are reluctant to disclose. Sorenson and Snow's (1991) research indicates that these children are by far the most common, but their work does not specifically address interview strategies to assist them.

Media other than anatomical dolls deserve study. Research on the utility of abuse-specific free drawing tasks, anatomical drawings, and computer-assisted interviews (DeVoe, 1995; Steward \& Steward, in press) should be undertaken.

Further, unless the field is to abandon the population of very young children who may have been sexu- 
ally abused, more research on what does work with them (e.g., Hewitt \& Friedrich, 1991) in addition to what does not (Bruck et al., 1995), is required.

In addition, research that assists school-aged children's ability to recall and report is of crucial importance. Studies have been conducted in the context of analogs (e.g., Saywitz, Nathanson, Snyder, \& Lamphear, 1993). These techniques need to be tested on actual cases.

Finally, as noted earlier, there is a paucity of research on the decision-making process. Systematic studies of how to decide whether or not a child has been sexually abused are also sorely needed.

The purpose of a section in Child Maltreatment dedicated to child interviewing is to inform readers about state-of-the-art practice and recent research findings. It is hoped that it will also inspire inquiry into areas noted here as needing further exploration.

\section{NOTE}

1. In the Jordan case, the adult against whom the first allegations were made was criminally convicted of sexually abusing some children, and there was protective services intervention to protect the children from further sexual abuse by their parents even though criminal charges were dropped against the parents. A number of the parents received immunity and underwent treatment (Humphrey, 1985). In the McMartin case, although the two persons tried were not convicted, when the 11 jurors were polled, 9 believed the children had been sexually abused (Waterman, Kelly, Olivieri, \& McCord, 1993). Further, a 7-year multimodal and longitudinal study of children from McMartin and other preschools found significant effects of the abuse that the McMartin children described (Waterman et al., 1993). One reason the children's accounts were doubted was that they described tunnels under the preschool. However, a controversial archaeological excavation under the preschool was conducted, and its (unpublished) report locates the tunnels described by the children (Earl, 1994; Stickel, 1993).

\section{REFERENCES}

Aman, C., \& Goodman, G. (1990). Children's use of anatomically detailed dolls to recount an event. ChildDevelopment, 61, 1859-1871.

American Academy of Child and Adolescent Psychiatry. (1990). Guidelines for the evaluation of child and adolescent sexual abuse (rev. ed.). Washington, DC: Author.

American Association for Protecting Children. (1987). Highlights of the official child neglect and abuse reporting: 1986. Denver, CO: American Humane Association.

American Professional Society on the Abuse of Children. (1990). Guidelines for psychosocial evaluation of suspected sexual abuse in young children. Chicago: Author.

American Professional Society on the Abuse of Children. (1995). Practice guidelines: Use of anatomical dolls in child sexual abuse assessments. Chicago: Author.

August, R., \& Foreman, B. (1989). A comparison of sexually abused and nonsexually abused children's behavioral responses to anatomically correct dolls. Child Psychiatry and Human Development, 20, 39-47.

Bays, J. (1990). Are the genitalia of anatomical dolls distorted? Child Abuse and Neglect, 14, 171-175.

Bays, J., \& Chadwick, D. (1993). Medical diagnosis of the sexually abused child. Child Abuse and Neglect, 17, 91-110.
Benedek, E., \& Schetky, D. (1985). Allegations of sexual abuse in custody disputes. In E. Benedek \& D. Schetky (Eds.), Emerging issues in child psychiatry and the law (pp. 146-156). New York: Brunner/Mazel.

Benedek, E., \& Schetky, D. (1987a). Clinical experience: Problems in validating allegations of sexual abuse. Part 1: Factors affecting the perception and recall of events. Journal of the American Academy of Child and Adolescent Psychiatry, 26, 912-915.

Benedek, E., \& Schetky, D. (1987b). Clinical experience: Problems in validating allegations of sexual abuse. Part 2; Clinical evaluation. Journal of the American Academy of Child and Adolescent Psychiatry, 26, 916-921.

Blush, G., \& Ross, K. (1986). SAID: Sexual Allegation In Divorce. Unpublished manuscript, Macomb Community College, Mt. Clemens, MI.

Boat, B., \& Everson, M. (1988). Interviewing young children with anatomical dolls. Child Welfare, 67, 337-352.

Boychuk, T., \& Stellar, M. (1992). Videotaped forensic interview of the school aged child. Unpublished manuscript, Center for Child Protection, St. Joseph's Hospital, Phoenix, AZ.

Brainerd, C., \& Orenstein, P. (1991). Children's memories for witnessed events. In J. Doris (Ed.), The suggestibility of children's recollections (pp. 10-20). New York: American Psychological Association.

Bremner, J. D., Krystal, J., Southwick, S., \& Charney, D. (1995). Functional neuroanatomical correlates of the effects of stress on memory. Journal of Traumatic Stress, 8, 527-554.

Bruck, M., Ceci, S., Francoeur, E., \& Renick, A. (1995). Anatomically detailed dolls do not facilitate preschoolers' reports of a pediatric examination involving genital touching. Journal of Experimental Psychology: Applied, 1(2), 95-109.

Bull, R. (1995). Innovative techniques for questioning children, especially those who are young and those who are learning disabled. In M. Zaragoza, J. Graham, G. Hall, R. Hirschman, \& Y. Ben-Porath (Eds.), Memory and testimony in the child witness (pp. 179-194). Thousand Oaks, CA: Sage.

Carter, C., Bottoms, B., \& Levine, M. (in press). Linguistic and socio-emotional influences on the accuracy of children's reports. Law and Human Behavior.

Ceci, S. (1993, October). Interview by John Stoessel on ABC television program 20/20.

Ceci, S., \& Bruck, M. (1993). The suggestibility of the child witness: A historical review and synthesis. Psychological Bulletin, 113, 403439

Ceci, S., \& Bruck, M. (1995). Jeopardy in the courtroom. New York: American Psychological Association.

Ceci, S., Huffman, M., Smith, E., \& Loftus, E. (1994). Repeatedly thinking about a non-event: Source misattributions among preschoolers. Consciousness and Cognition, 3, 388-407.

Ceci, S., Loftus, E., Leichtman, M., \& Bruck, M. (1995). The role of source misattribution in the creation of false beliefs among preschoolers. Unpublished manuscript, Department of Human Development, Cornell University.

Clarke-Stewart, A., Thompson, W., \& Lapore, S. (1989, April). Manipulating children's interpretations through interrogation. Paper presented at the meeting of the Society for Research on Child Development, Kansas City, MO.

Cohn, D. (1991). Anatomical doll play of preschoolers referred for sexual abuse and those not referred. Child Abuse and Neglect, 15, 455-466.

Conte, J., \& Berliner, L. (1986). The impact of sexual abuse on children (Final Report No. MH37133). Washington, DC: National Institute of Mental Health.

Conte, J., Sorenson, E., Fogarty, L., \& Dalla Rosa, J. (1988). Evaluating children's reports of sexual abuse: Results from a survey of professionals. Unpublished manuscript (expanded version of 1991 published article), School of Social Service Administration, University of Chicago.

Conte, J., Sorenson, E., Fogarty, L., \& Dalla Rosa, J. (1991). Evaluating children's reports of sexual abuse: Results from a survey of professionals. American Journal of Orthopsychiatry, 61, 428-437. 
Corwin, D. (1988). Early diagnosis of child sexual abuse: Diminishing the lasting effects. In G. Wyatt \& G. Powell (Eds.), The lasting effects of child sexual abuse (pp. 251-270). Newbury Park, CA.: Sage.

Corwin, D., Berliner, L., Goodman, G., Goodwin, J., \& White, S. (1987). Sexual abuse allegations in custody cases: No easy answers. Journal of Interpersonal Violence, 2, 91-105.

DeVoe, E. (1995). Final report: Computer assisted interviewing with children who may have been sexually abused. Unpublished manuscript, School of Social Work, University of Michigan.

De Young, M. (1986). A conceptual model for judging the truthfulness of a young child's allegation of sexual abuse. American Journal of Orthopsychiatry, 56, 550-559.

Earl, J. (1995). The dark truth about the "dark tunnels of McMartin." Issues in Child Abuse Accusation, 7(2), 76-131.

Everson, M. (1994, January). Children's fantasy-like statements in sexual abuse evaluations. Presented at APSAC Institute: Art and Science of Forensic Interviewing, San Diego Conference on Responding to Child Maltreatment, San Diego.

Everson, M. (1995, January). Concerning practices using anatomical dolls. Presented at APSAC Institute: Art and Science of Forensic Interviewing, San Diego Conference on Responding to Child Maltreatment, San Diego.

Everson, M., \& Boat, B. (1994). Putting the anatomical doll controversy in perspective: An examination of the major doll uses and related criticisms. Child Abuse and Neglect, 18, 113-130.

Faller, K. C. (1984). Is the child victim of sexual abuse telling the truth? Child Abuse and Neglect, 8, 473-481.

Faller, K. C. (1988). Criteria for judging the credibility of children's statements about their sexual abuse. Child Welfare, 7, 389-401.

Faller, K. C. (1990). Understanding child sexual maltreatment. Newbury Park, CA: Sage.

Faller, K. C. (1993). Child sexual abuse: Intervention and treatment issues. Washington, DC: U.S. Department of Health and Human Services.

Faller, K. C. (1994). Child sexual abuse: How to decide. Violence Update, 4(6), 1-2, 10.

Faller, K. C. (1996). Study guide: Evaluating children suspected of having been sexually abused. Thousand Oaks, CA: Sage.

Faller, K. C., \& Corwin, D. (1995). Children's interview statements and behaviors: Role in identifying sexually abused children. Child Abuse and Neglect, 19, 71-82.

Faller, K. C., Froning, M., \& Lipovsky, J. (1991). The parent-child interview: Its use in deciding sexual abuse by the parent. American Journal of Orthopsychiatry, 61, 552-557.

Fivush, R. (1993). Developmental perspectives on autobiographical recall. In G. Goodamn \& B. Bottoms (Eds.), Child victims, child witnesses (pp. 1-24). New York: Guilford.

Fivush, R., \& Shukat, J. (1995). Content, consistency, and coherence of early autobiographical recall. In M. S. Zaragosa, J. R. Graham, G.C.N. Hall, R. Hirschman, \& Y. S. Ben-Porath (Eds.), Memory and testimony in the child witness (pp. 5-23). Thousand Oaks, CA: Sage.

Gardner, R. (1991). Sex abuse hysteria: Salem witch trials revisited. Cresskill, NJ: Creative Therapeutics.

Gardner, R. (1992a). The parental alienation syndrome. Cresskill, NJ: Creative Therapeutics.

Gardner, R. (1992b). True and false allegations of child sex abuse. Cresskill, NJ: Creative Therapeutics.

Goodman, G., Bottoms, B., Schwartz-Kennedy, B., \& Rudy, L. (1991). Children's testimony for a stressful event: Improving children's reports. Journal of Narrative and Life History, 1, 69-99.

Goodman, G., \& Clarke-Stewart, A. (1991). The suggestibility of children's testimony: Implications for sexual abuse investigations. In J. Doris (Ed.), The suggestibility of children's recollections (pp. 92-105). New York: American Psychological Association.

Goodman, G., Hirschman, J., Hepps, D., \& Rudy, L. (1991). Children's memory for a stressful event. Merrill-Palmer Quarterly, 37, $109-158$
Gordon, B., Ornstein, P., Nida, R., Follmer, A., Crenshaw, C., \& Albert, G. (1993). Does the use of dolls facilitate children's memories of visits to the doctor? Applied Cognitive Psychology, 7 , 459-474.

Green, A. (1986). True and false allegations of sexual abuse in child custody disputes. Journal of the American Academy of Child Psychiatry, 25, 449-455.

Hanson, G. (1988). The sex abuse controversy: Letter to the editor Journal of the American Academy of Child and Adolescent Psychiatry, $27,258$.

Haynes-Seman, C., \& Baumgartner, D. (1995). Children speak for themselves. New York: Brunner/Mazel.

Heiman, M. (1992). Annotation: Putting the puzzle together: Validating allegations of child sexual abuse. Journal of Child Psychology and Psychiatry, 33, 311-329.

Henderson, J. (1972). Incest: A synthesis of the data. Canadian Psychiatric Association Journal, 17, 299-313.

Hewitt, S., \& Friedrich, W. (1991). Assessing sexual abuse in very young children. Unpublished manuscript. (Available from $S$ Hewitt, Ph.D., 3300 Edinborough Way, Suite 418, Edina, MN 55435)

Hollingsworth, J. (1986). Unspeakable acts. New York: Congdon \& Weed.

Humphrey, H. (1985). Report on the Scott County investigations. Minneapolis: Minnesota Attorney General's Office.

Jampole, L., \& Webber, M. (1987). An assessment of the behavior of sexually abused and non-sexually abused children with anatomically correct dolls. Child Abuse and Neglect, 11, 187-192.

Jones, D., \& McGraw, E. M. (1987). Reliable and fictitious accounts of sexual abuse to children. Journal of Interpersonal Violence, 2 $27-45$.

Jones, D., \& McQuiston, M. (1985). Interviewing the sexually abused child. Denver, CO: C. H. Kempe National Center for the Prevention and Treatment of Child Abuse and Neglect.

Jones, D., \& McQuiston, M. (1986). Interviewing the sexually abused child (2nd ed.). Denver, CO: C. H. Kempe National Center for the Prevention and Treatment of Child Abuse and Neglect

Katz, S., Schonfeld, D., Levanthal, J., \& Cicchetti, D. (1995). The accuracy of children's reports with anatomically correct dolls. Developmental and Behavioral Pediatrics, 16(2), 71-76.

Kempe, C.'H., Silverman, F., Steele, B., Droegmueller, W., \& Silver H. K. (1962). The battered child syndrome. Journal of the American Medical Association, 181, 17-24.

Klajner-Diamond, H., Wehrspann, W., \& Steinhauer, P. (1987). Assessing the credibility of young children's allegations of sexual abuse: Clinical issues. Canadian Journal of Psychiatry, 32, 610-614.

Lanning, K. \& Hazelwood, R. (1988, September). The maligned investigator of criminal sexuality. F.B.I. Law Enforcement Bulletin, pp. 1-10.

Lawson, L., \& Chaffin, M. (1992). False negatives in sexual abuse disclosure interviews. Journal of Interpersonal Violence, 7, 532-542.

Levanthal, J., Bentovim, A., Elton, A., Trantner, M., \& Reed, L. (1987). What to ask when sexual abuse is suspected. Archives of Disease in Childhood, 62, 1188-1195.

Leichtman, M., \& Ceci, S. (1995). The effects of stereotypes and suggestions on preschoolers' reports. Developmental Psychology, $31,568-578$.

MacFarlane, K., \& Waterman, J. (1986). Sexual abuse of young children. New York: Guilford.

Mansell, L. (1990). Naptime. New York: William Morrow.

McCurdy, K., \& Daro, D. (1994). Current trends in child abuse reporting and fatalities. Chicago: National Committee for the Prevention of Child Abuse.

Melton, G., \& Limber, M. (1989). Psychologists' involvement in cases of child maltreatment. American Psychologist, 44, 1225-1233.

Myers, J.E.B. (1992). Legal issues in child abuse and neglect practice. Newbury Park, CA: Sage.

Myers, J.E.B. (Ed.). (1994). Backlash. Newbury Park, CA: Sage. 
Myers, J.E.B., \& Peters, W. (1987). Child abuse reporting: Legislation in the 1980s. Denver, CO: American Association for Protecting Children.

National Center on Child Abuse and Neglect. (1995). Child maltreatment 1993: Reports from the states to the National Center on Child Abuse and Neglect. Washington, DC: U.S. Department of Health and Human Services.

Rabinowitz, D. (1990, May) Out of the mouths of babes and into a jail cell. Harper's Magazine, pp. 52-63.

Raskin, D., \& Esplin, P. (1991). Assessment of children's statements of sexual abuse. In J. Doris (Ed.), The suggestibility of children's recollections (pp. 153-164). New York: American Psychological Association.

Saywitz, K., Goodman, G., Nicholas, E. \& Moan, S. (1991). Children's memory for a genital examination: Implications for child sexual abuse cases. Journal of Consulting and Clinical Psychology, 59, 682-691.

Saywitz, K, Nathanson, R., Snyder, L., \& Lamphear, V. (1993). Preparing children for the investigative and judicial process: Improving communication, memory, and emotional resiliency: Final report to the National Center on Child Abuse and Neglect. Unpublished manuscript, Department of Psychiatry, UCLA School of Medicine.

The Scott County case: How it grew; why it died. (1985, June 29). Minneapolis Star and Tribune.

Sgroi, S. (1980). Sexual abuse of children: The last frontier of child abuse. In L. Schultz (Ed.), Sexual victimology of youth. Springfield, IL: Charles C Thomas.

Sgroi, S., Porter, F., \& Blick, L. (1982). Validation of sexual abuse. In S. Sgroi (Ed.), Handbook of clinical intervention in child sexual abuse (pp. 39-80). Lexington, MA: Lexington Books.

Sink, F. (1988). A hierarchical model for evaluation of child sexual abuse. American Journal of Orthopsychiatry, 58, 129-135.

Sivan, A., Schor, D., Koeppl, G., \& Noble, L. (1988). Interaction of normal children with anatomical dolls. Child Abuse and Neglect, $12,295-304$

Sorenson, T., \& Snow, B. (1991). How children tell: The process of disclosure in child sexual abuse. Child Welfare, 70, 3-15.
Steward, M. S., \& Steward, D. S. (in press). Interviewingyoung children about body touch and handling. Monograph series of the Society for Research on Child Development.

Stickel, G. (1993). Archaeological investigations of the McMartin Preschoolsite: Manhattan Beach, California. Unpublished manuscript, Department of Archeology, University of California, Los Angeles.

Tufts New England Medical Center, Division of Child Psychiatry. (1984). Unconfirmed cases of sexual abuse. In Sexually exploited children: Service and research project (final report). Washington, DC: Office of Juvenile Justice and Delinquency Prevention.

Underwager, R., \& Wakefield, H. (1988). Accusations of child sexual abuse. Springfield, IL: Charles C Thomas.

Van der Kolk, B. (1994). The body keeps score: Memory and the psychobiology of posttraumatic stress. Harvard Review of Psychiatry, 1(5), 253-265.

Van der Kolk, B., \& Fisler, R. (1995). Dissociation and the fragmentary nature of traumatic memories: Overview and exploratory study. Journal of Traumatic Stress, 8, 505-526.

Waterman, J., Kelly, R., Olivieri, M. K., \& McCord, J. (1993). Behind the playground walls: Sexual abuse in preschools. New York: Guilford.

Wehrspann, W., Steinhauer, P., \& Klajner-Diamond, H. (1987). Criteria and methodology for assessing credibility of sexual abuse allegation. Canadian Journal of Psychiatry, 32, 615-623.

White, S., \& Quinn, K. (1988). Investigatory independence child sexual abuse evaluation: Conceptual considerations. Bulletin of the American Academy of Psychiatry and the Law, 16, 269-278.

White, S., Strom, G., Santilli, G., \& Halpin, B. (1986). Interviewing young sexual abuse victims with anatomically correct dolls. Child Abuse and Neglect, 10, 519-529.

Yuille, J. (1988). The systematic assessment of children's testimony. Canadian Psychology, 29, 247-259.

Kathleen Coulborn Faller, Ph.D., Professor, School of Social Work, University of Michigan. 